\section{Treatment of Calcinosis Circumscripta with Probenecid}

\author{
C. E. DENT, T. C. B. STAMP
}

British Medical fournal, 1972, 1, 216-218

\section{Summary}

A 23-year-old woman presented with an 11-year history of peripheral joint pains and stiffness slowly progressing to the development of gross calcinosis circumscripta. She had no definite evidence of systemic scleroderma. She was first treated for one year with frequent intravenous sodium EDTA, which increased urinary calcium and enhanced negative calcium balance but did not lessen her calcinosis. She was then treated with probenecid up to $2 \mathrm{~g}$ daily and her calcinosis lessened steadily over three years. Plasma levels of both phosphorus and urate fell during this time.

\section{Introduction}

Ectopic calcific masses of hydroxyapatite may accumulate in soft tissues of the extremities producing calcinosis circumscripta. Extensive bone resorption in the phalanges and sclerodactylia may also occur both with and without evidence of generalized scleroderma (Muller et al., 1959). Treatment of this chronic incapacitating condition is generally thought to be unavailing. One logical therapeutic approach lies in an attempt to lower the calcium/phosphorus solubility product in plasma by depleting the body of calcium or phosphorus or both.

Probenecid may lower the plasma phosphorus in hypoparathyroidism (Pascale et al., 1954; Dubin et al., 1956), but this effect has not been established in normal subjects (Spurr et al., 1954; Dubin et al., 1956). We report a case in which pronounced, albeit still incomplete, dissolution of ectopic calcification occurred during three years' treatment with probenecid together with a low calcium diet. Previous attempted therapy over one year with a calcium chelating agent, sodium ethylenediaminetetraacetate ( $\mathrm{Na}$ EDTA), had failed to alter the radiological appearances of the deposits.

\section{Case Report}

A 12-year-old girl developed generalized joint pains and stiffness most noticeable in the extremities. Swelling followed in the interphalangeal joints and nodules developed at first over the elbow and one internal malleolus. The E.S.R. was $29 \mathrm{~mm}$ in one hour and leucocytes were $18,500 / \mathrm{mm}^{3}$, with $64 \%$ polymorphs. Serum proteins showed a pronounced increase in $\alpha_{2}$-globulins. Still's disease was diagnosed and she was treated for a time with prednisone. Her symptoms progressed, however, and the E.S.R. remained raised. By the age of 16 years nodules had developed over her

Medical Unit and Department of Human Metabolism, University College Hospital, London W.C.1

C. E. DENT, M.D., F.R.S., Professor of Human Metabolism

T. C. B. STAMP, M.SC., M.R.C.P., Wellcome Research Fellow fingers, and at 18 years $x$-ray films showed erosion of the metacarpals and partial disappearance of the terminal phalanges, with calcinosis at the finger-tips. Movement was limited at the wrists and elbows, and nodules developed in her back over the spinous processes. A year later the phalangeal nodules began intermittently to discharge a chalky, white material. During the following four years her condition slowly worsened. She had never suffered from Raynaud's phenomenon and apart from severe emotional problems there were no other symptoms.

She was first seen at University College Hospital in 1965 at the age of 23. Her hands were grossly deformed-the fingers were shortened, due mainly to resorption of the phalanges, but there was also a dislocation of one metacarpophalangeal joint and disorganization of another. Numerous hard nodules were also present. Joints of the upper extremity were not affected proximal to the elbows, the skin was warm and fully mobile where not overlying a nodule, and there was no telangieciasia or gangrene. Physical examination showed no other abnormality.

Investigations producing normal results included full blood count, E.S.R. ( $4 \mathrm{~mm}$ in one hour), serum proteins, all tests for rheumatoid and antinuclear factors, plasma urea, electrolytes, and routine urine function studies. Plasma calcium was $8.7 \mathrm{mg} /$ $100 \mathrm{ml}$ (S.G. 1025), phosphorus $4.7 \mathrm{mg} / 100 \mathrm{ml}$, alkaline phosphatase 7 K.A. units, and the urate $5.9 \mathrm{mg} / 100 \mathrm{ml}$. Results of a full gastrointestinal $x$-ray examination were normal. On the other hand, the chest $x$-ray film showed minor streaky basal opacities, and the diffusion of carbon monoxide at rest and after exercise was 10.4 and $13.5 \mathrm{ml} / \mathrm{min} / \mathrm{mm} \mathrm{Hg}$ pressure of $\mathrm{CO}$ respectively (probably abnormal). $X$-ray crystallography of the chalky discharge showed pure hydroxyapatite (Dr. J. Sutor).

Metabolic balance studies (Fig. 1) showed a negative calcium balance, with high faecal and low urinary calcium. She was treated with intravenous Na EDTA in increasing doses and negative balance increased owing to a sharp rise in urinary calcium. Six hours after an EDTA infusion $(70 \mathrm{mg} / \mathrm{kg}$ in two hours) plasma calcium fell from $8.8 \mathrm{mg}$ to $7.2 \mathrm{mg} / 100 \mathrm{ml}$ but rose to pretreatment levels by the following morning.

She was discharged on a permanent low-calcium diet and for one year received single monthly infusions of Na EDTA $(4 \mathrm{~g})$. The

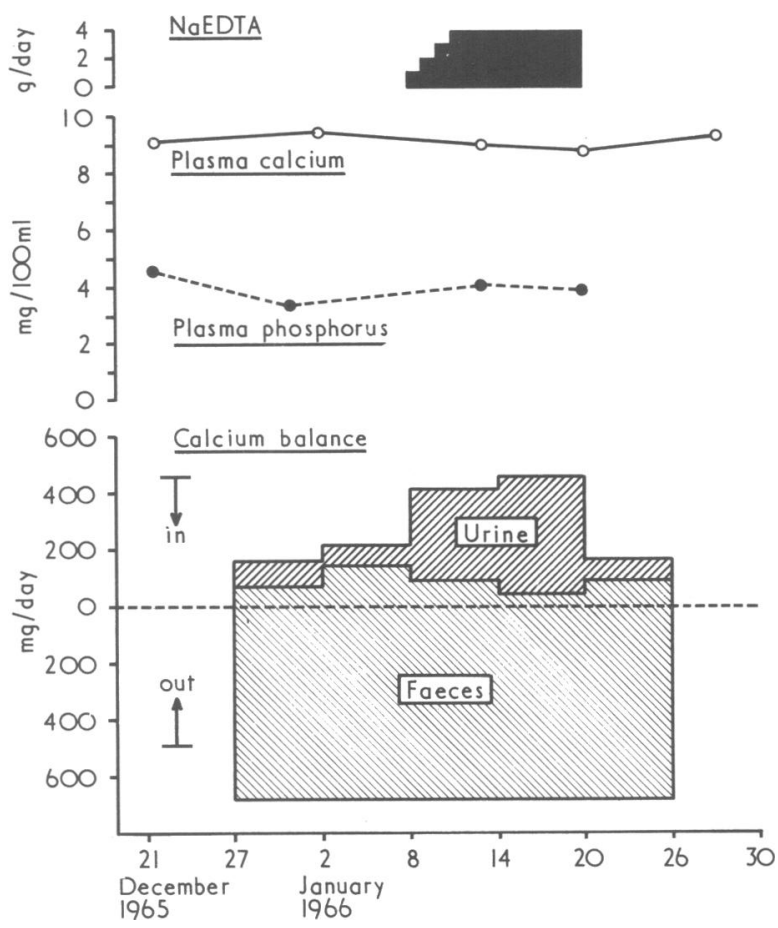

FIG. 1-Metabolic data obtained on patients' first admission. 
radiological picture, however, did not improve (Fig. 2). In January 1967 she was started instead on probenecid in gradually increasing doses. She later steadily and greatly improved (Fig. 3). Studies of renal phosphorus excretion by the technique of Stamp and Stacey (1970) after treatment with probenecid for two years showed a completely normal theoretical renal phosphorus threshold of 3.6 $\mathrm{mg} / 100 \mathrm{ml}$, glomerular filtration rate $102 \mathrm{ml} / \mathrm{min}$, and $\operatorname{TmP} 4.5$ $\mathrm{mg} / \mathrm{min} 1.73 \mathrm{~m}^{2}$. Changes in plasma calcium, phosphorus, and
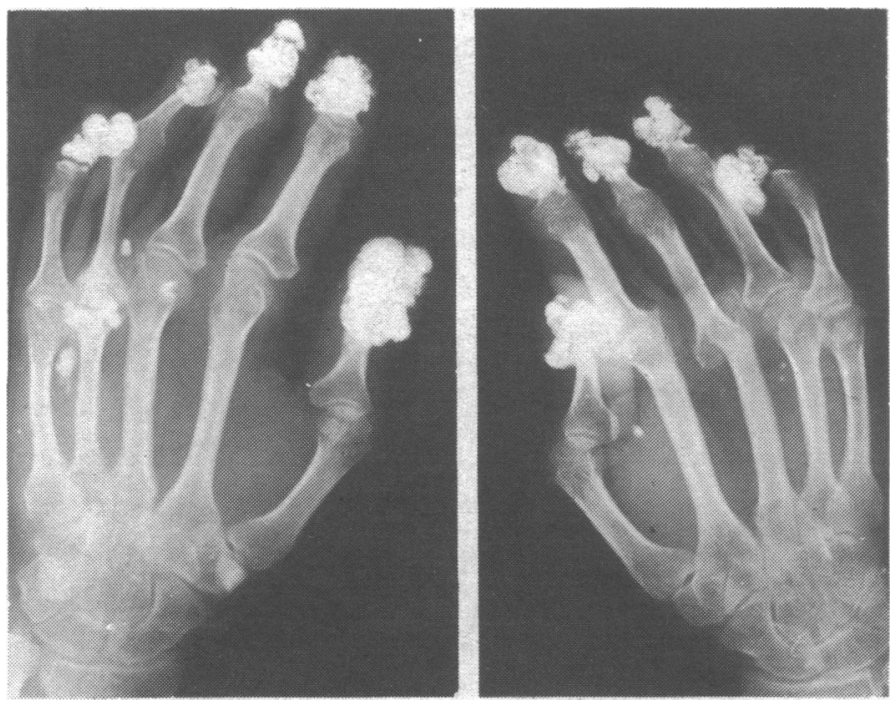

FIG. 2-X-ray picture of hands in Jaunary 1967 at end of treatment with EDTA for 8 months. No change was seen in calcific deposits during this period.
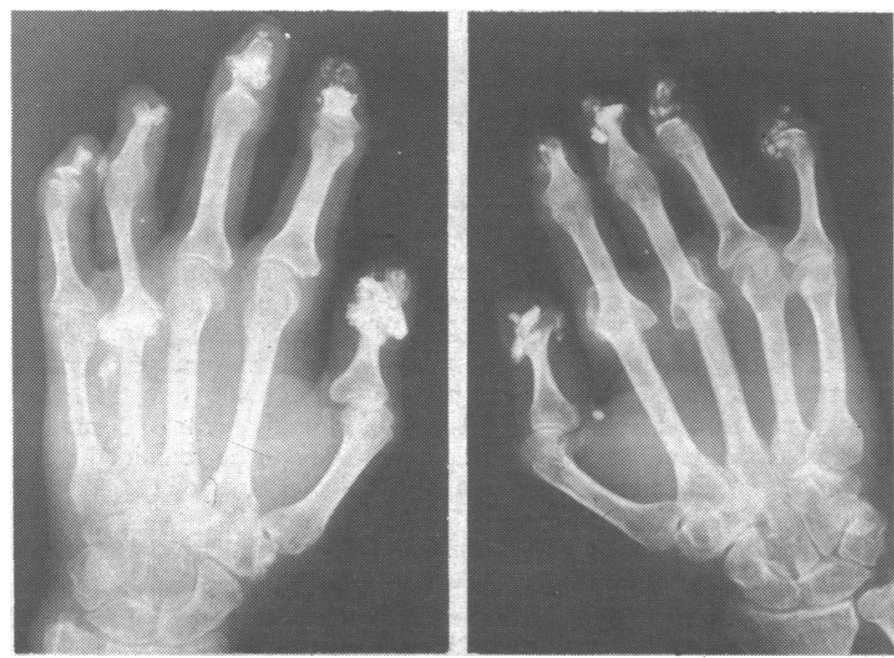

71G. 3-X-ray picture of hands in November 1970 after treatment with probenecid. Dissolution of deposits, fast at first, had been maintained at a slower rate for 3 years.

urate during the whole of her follow-up are shown in Fig. 4. During that time there was no change in her general physical condition, which remained good. She was greatly heartened by the improved mobility and appearance of her fingers.

\section{Discussion}

This case is of interest from both pathological and therapeutic standpoints. While the initial onset of the disease and subsequent development of calcinosis is a recognized pattern in scleroderma (Tumulty, 1968) this case was unusual in having no history of Raynaud's phenomenon, no telangiectasia, and little or no evidence of sclerodactylia. The almost isolated combination of gross calcinosis and phalangeal resorption, "autoamputation," thus appears highly unusual
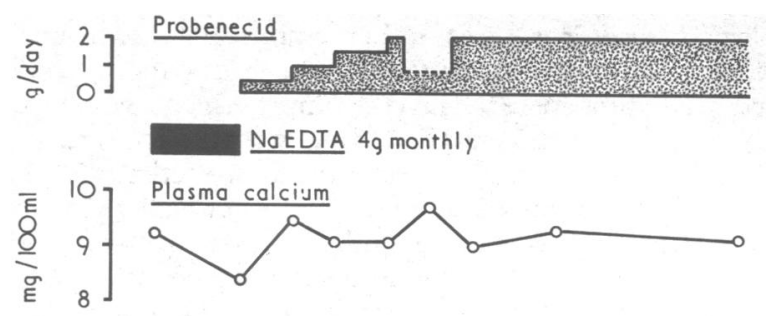

FIG. 4-Plasma levels and treatment during follow-up. The rise in plasma urate in March to July 1969 cannot be explained, but irregular medication may have been the cause, as occurred in mid-1968.

(Muller et al., 1959; Sackner, 1966; Tumulty, 1968). Broadly, however, this disorder is known to run a benign course (Muller et al., 1959; Dellipiani and George, 1967) without exacerbations or spontaneous remissions.

Studies with isotopic calcium-47 have suggested that overabsorption of calcium occurs from the intestine in this condition (Avioli et al., 1965; Marks, 1970). This was clearly not the case in the present patient, in whom faecal calcium was a little greater than calcium intake.

The treatment of calcinosis in all its various forms has been disappointing. Steroids are usually unsuccessful (Transactions, 1967). It seems clear that there is a close relation between the calcium phosphorous product in the plasma and the tendency for ectopic calcification to occur. This has been shown in renal failure, and we have a most convincing follow-up report on a patient with primary hyperparathyroidism treated since 1957 with oral sodium phosphate (Dent, 1962-Fig. 17, patient Emily P.). Since that report we twice produced gross ectopic calcifications in soft tissues by overdosage with phosphate, and both times the calcification practically disappeared on reducing the phosphate intake, thus also establishing the potential reversibilty of this unpleasant feature. Because of that experience we began in this patient by giving large doses of Na EDTA. This produced, as is inevitable, hypocalcaemia, hypercalciuria, and a strongly negative calcium balance, but had no effect on her lesions.

Phosphate depletion is theoretically more attractive than calcium depletion, and a ready means of inducing this is by the administration of aluminium hydroxide gel (Aludrox). This treatment was successfully used in a case of calcinosis universalis (Nassim and Connolly, 1970). The compound is unpleasant to take, however, and though we continue to use it we have a patient under our care with gross calcinosis cutis and some evidence of systemic scleroderma in whom Aludrox has been ineffective in relieving calcinosis over a period of 18 months to date (unpublished data).

Probenecid may lower the plasma phosphorus in hypoparathyroidism (Pascale et al., 1954; Dubin et al., 1956) and published data have not satisfactorily excluded a minor phosphaturic effect in normal subects. This patient had a rather high plasma phosphorus and low normal calcium which at first suggested to us a mild degree of hypoparathyroidism, which if present might have facilitated the deposition of ectopic calcium salts mainly caused by her 
primary disease. For these rather empirical reasons and because of its greater acceptability to the patient she was treated with probenecid, and the improvement was striking. It is possible to conclude from Fig. 4 that in company with the fall in plasma urate a significant reduction in plasma phosphorus also occurred without significant change in plasma calcium. Renal phosphate handling, however, was entirely within the normal range while taking probenecid. We did not obtain a figure before probenecid so the exact effect of the drug in facilitating the dissolution of the calcific deposits is not known.

Whatever the mechanism of the drug action the results are thought convincing enough to suggest a direct causal effect on the dissolution of the calcinosis. The patient's history suggested that the changes originally present were of long duration. No change occurred during the first year of treatment with Na EDTA, nor indeed by the October $1967 x$-ray film (not shown here) taken after nine months of slowly increasing probenecid. More rapid dissolution occurred later only when the full dose of $2 \mathrm{~g}$ a day had been reached. It seems difficult to attribute the response to some other unknown cause, and we are unaware that spontaneous dissolution has ever been described.

Until adequate therapy or prevention is available for the tissue damage itself, which so often leads to calcinosis, attempts to inhibit calcification will remain a therapeutic necessity. Further trials of Aludrox or probenecid are thus warranted because we believe that these drugs act by lowering $\mathrm{Ca} \times \mathbf{P}$ which tends to redissolve the deposits when formed rather than as a mechanism which will prevent the deposits. Other drugs, including salicylates (Somogyi et al.,
1969) and diphosphonates (Francis et al., 1969), have also been shown experimentally to inhibit soft tissue calcification, and their therapeutic trial in human calcinosis is also indicated.

We are grateful to the dietitians and laboratory and nursing staff of the metabolic ward, U.C.H., for their continuous cooperation. T.C.B.S. acknowledges support of an M.R.C. grant during part of this work. Professor E. G. L. Bywaters kindly came to see the patient on her first admission to help us in making a diagnosis. We gratefully acknowledge the continuing help and support of the patient's general practitioner, Dr. Kenneth Milne.

\section{References}

Avioli, L. V., McDonald, J. E., Singer, R. A., and Henneman, R. H. (1965). Fournal of Clinical Investigation, 44, 128 .

Dellipiani, A. W., and George, M. (1967). British Medical fournal, 4, 334. Dent, C. E. (1962). British Medical fournal, 2, 1419, 1495.

Dubin, A., Kushner, D. S., Bronsky, D., and Pascale, L. R. (1956). Metabolism: Clinical and Experimental, 5, 703.

Francis, M., Russell, R. G. G., and Fleisch, H. (1969). Science, 165, 1264.

Marks, J. (1970). British fournal of Dermatology, 82, 1 .

Muller, S. A., Brunstig, L. A., and Winkelmann, R. K. (1959). Archives of Dermatology, 80, 15.

Nassim, J. R., and Connolly, C. K. (1970). Archives of Disease in Childhood,

45, 118. and Experimental, 3, 462.

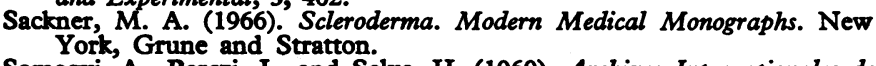

Somogyi, A., Berczi, I., and Selye, H. (1969). Archives Internationales de Pharmacodynamie et de Therapie, 177, 211.

Spurr, C. L., Ford, R. V., and Moyer, J. H. (1954). American fournal of the Medical Sciences, 228, 256.

Stamp, T. C. B., and Stacey, T. E. (1970). Clinical Science, 39, 505.

Transactions of the St. Fohn's Hospital Dermatological Society, 1967, 53,

Tumulty, P. A. (1968). Fohns Hopkins Medical fournal, 122, 236.

\section{MEDICAL MEMORANDA}

\section{Cataract after Busulphan Treatment}

\author{
M. P. RAVINDRANATHAN, V. J. PAUL, \\ E. T. KURIAKOSE
}

British Medical fournal, 1972, 1, 218-219

Busulphan, first introduced into clinical practice by Galton in 1953, is the drug of choice in the treatment of chronic myeloid leukaemia. Cataract as a toxic effect of prolonged busulphan therapy has been reported only rarely (Podos and Canellos, 1969). This report describes the case of a young adult with chronic myeloid leukaemia who developed mature cataract in both eyes during busulphan therapy.

\section{Case Report}

A male university student aged 19 was referred to one of us (V.J.P.) in December 1965 because of increasing lassitude for one month. On physical examination he was found to be anaemic, the liver was enlarged up to $5 \mathrm{~cm}$ below the right costal margin, and the spleen was enlarged up to the level of the umbilicus. There were no ocular changes and the fundi were normal. Laboratory investigations were: Haemoglobin $10 \mathrm{~g} / 100 \mathrm{ml}$, total leucocyte

District Headquarters Hospital, Cochin-II, Kerala, India M. P. RAVINDRANATHAN, M.B., B.S., M.R.C.P., Assistant Physician V. J. PAUL, M.B., B.S., M.R.C.P., Consulant Physician E. T. KUROAKOSE, M.S., P.I.C.S., Consultant Ophthalmologist count $150,000 / \mathrm{mm}^{3}$ (97,000 myelocytes, 15,000 myeloblasts, 22,500 polymorphs), platelet count $360,000 / \mathrm{mm}^{3}$, sternal bone marrow typical of chronic myeloid leukaemia, urine analysis normal, blood urea $40 \mathrm{mg} / 100 \mathrm{ml}$, and stool negative for ova and cysts.

On 14 January 1966 he was started on busulphan $8 \mathrm{mg}$ daily with a weekly check on blood counts. Towards the end of the first month his total leucocyte count had fallen to $26,400 / \mathrm{mm}^{3}$ and the dose was reduced to $2 \mathrm{mg}$ daily. Subsequently with $1-2 \mathrm{mg}$ of busulphan daily and occasional blood transfusion he remained well. The dose of busulphan was adjusted to keep the total leucocyte count near $10,000 / \mathrm{mm}^{3}$.

In March 1970 he noted failing vision in the right eye and three months later in the left eye. On examination this was found to be due to an early cataract. The fasting blood sugar was $90 \mathrm{mg}$, postprandial $135 \mathrm{mg}$, glucose tolerance test was normal, and the serum calcium was $10.5 \mathrm{mg} / 100 \mathrm{ml}$. There was no history of trauma to the eyes or administration of drugs other than busulphan. Failure of vision in both eyes progressed rapidly. On 16 September 1970 an extracapsular extraction of a mature cataract was done in the right eye and on 14 March 1971 the cataract in the left eye was also removed. During both operations it was found that the nucleus of the cataract was small and the cortex, of semifluid consistency, easily washed away after the delivery of the nucleus. The lens capsule was seen to be very thin and he had $6 / 6$ vision without needling and with the aid of glasses.

Five months after the second operation the patient remained well and was in the sixth year of survival after the diagnosis of chronic myeloid leukaemia.

\section{Comment}

Though busulphan had been found to be cataractogenic to experimental animals (Sallmann, 1957) the development of cataract in patients on busulphan therapy was reported only recently (Podos and Canellos, 1969). These authors 